\title{
O Trabalho de Ator e a Zona de Turbulência
}

\author{
Renato Ferracini
}

O tempo do poeta: viver em dia; e vivê-lo simultaneamente, de duas maneiras contraditórias, como se fosse interminável e como se fosse acabar agora mesmo.

Octavio Paz.

( que acontece com o ator em Estado Cênico? Mais. Como poderemos pensar esse espaço "entre" corpo do ator com seus continuuns de recriação de açōes e o público que o acompanha? Claramente não responderei aqui essa questão, mas posso tentar realizar algumas ponderaçóes e mesmo reflexóes criativas sobre essa zona de difićlima conceituação, principalmente quando pensada a partir do trabalho do ator.
Ao iniciar um espetáculo, o ator recria em seu corpo um estado inicial e, a partir desse instante primeiro, toda uma linha de matrizes ${ }^{1} \mathrm{e}$ açōes físicas são recriadas a partir de um continuum, de uma linha helicoidal de ativação/reativação de estados, ações e matrizes amalgamados em suas corporeidades/fisicidades, todos esses elementos mergulhadas em um estado intensivo e de zona de vizinhança comum e virtual $^{2}$ com o público e com o espaço. $\mathrm{O}$ ator se "dilui" nessa zona através e por entre as fisicidades, corporeidades e estados que mergulham esse corpo-em-estado-cênico nessa zona virtual (intensiva) e atual (física e espaço/temporal) ao mesmo tempo. E, também, não devemos pensar que o ator, mergulhado, diluído nessa zona

Renato Ferracini é ator e perquisador do LUME, da Unicamp, e cursa o doutorado no Instituto de Artes da Unicamp.

1 Dentro do âmbito de trabalho do LUME podemos dizer que uma ação física e/ou vocal orgânica, pesquisada e codificada por um ator e que dinamiza seus campos intensivos potenciais, é chamada de "matriz". Se procurarmos no dicionário, encontraremos algumas das razões de essa palavra ter sido utilizada para definir uma açáo física orgânica: "Matriz: órgão das fêmeas dos mamíferos onde se gera o feto; útero; madre [...] que é fonte ou origem; principal; primordial". Assim, a Matriz é entendida como o material inicial, principal e primordial; é como a fonte de material do ator, à qual ele poderá recorrer, sempre que desejar, para a construção de qualquer trabalho cênico. A matriz é a própria ação físical vocal, viva e orgânica, codificada. Dessa forma, cada ator possui um conjunto de matrizes, que se torna seu vocabulário vivo de comunicação cênica - seu vocabulário expressivo a ser recriado no momento do corpo-em-estado-cênico.

2 O conceito de virtual é uma noção importante aqui. Ele realiza-se primeiramente como uma parte constituinte do objeto real, criando um duplo atual/virtual sempre presente no objeto. Sendo assim, o próprio corpo é formado por virtuais que o atravessam e também por atuais que o definem. Em segundo 
intensiva e nesse continuum de recriação está em um suposto estado de "transe" ou completamente "desligado" do mundo. Não. Primeiramente porque essa zona Intensiva não é um mundo outro, mas é completamente imanente ao corpo do ator. É um transbordamento de seu próprio corpo cotidiano, linha de fuga de seu plano de organização. Portanto, ao mesmo tempo que o ator, em Estado Cênico, está vivenciando uma absoluta condição de criação, entrega e diluição de seu corpo nessa zona intensiva, tudo também encontra-se em uma condição de completa "consciência" desse próprio estado de criação, do outro ator, do público e do espaço. Isso significa que ao mesmo tempo que minhas ações e estados afetam o espaço e o outro (ator ou público) esse mesmo outro (ator e público) e o espaço também me afetam, fazendo com que desvios, lanças, setas, buracos, modificações e recriações de minhas ações e estados sejam alterados, redimensionados algumas vezes de maneira microscópica, outras vezes de forma macroscópica, dentro do próprio Estado Cênico. A essa zona que está "entre" minhas ações físicas, matrizes, estados, o espaço, o outro ator e o público, e que afeta e é afetada, chamo de zona de turbulência.

As matrizes, por mais codificadas que sejam, devem sempre conter essa zona de abertura e jogo com o espaço e com o outro em todos os níveis. Uma zona de modificações e redimensionamento instantâneo em potência na própria matriz. Se não possibilito essa abertura, esse " $\mathrm{fa}$ zer pra fora", essa zona de afetar e ser afetado, não consigo, como ator, construir um corpoem-estado-cênico. Assim, esse corpo-em-estadocênico não pode ser reduzido às matrizes e ações físicas, mas sim, habita as matrizes junto a um continuum de recriação dentro dessa zona de turbulência que faz com que o próprio corpoem-estado-cênico seja sempre lançado em zonas de recriação: seja dele mesmo em relação ao corpo cotidiano, seja dele mesmo em relação a ele mesmo. Recriação sobre recriação. Mas falar simplesmente que o corpo-em-estado-cênico está dentro dessa zona não está totalmente correto. $\mathrm{Na}$ verdade o corpo-em-estado-cênico, ao mesmo tempo, cria, habita e é essa zona de turbulência. Esse estado cênico se auto gere e se desvanece em instantes continuuns, agencia-se sobre momentos de desterritorialização, ao mesmo tempo em que esses mesmos continuuns desvanecentes geram também essa zona de turbulência, criando um estado de jogo entre o corpo-em-estado-cênico em contato com o outro ator, o público e o espaço. Assim, essa zona de turbulência estará sempre vinculada a esse continuum de auto-criaçáo. $\mathrm{O}$ ator deve ser capaz de gerar a zona de turbulência e ao mesmo tempo "entrar" dentro dela, deixando-se afetar e afe-

lugar o virtual não deve ser confundido e nem colocado em oposição ao real. O virtual não se opõe ao real, mas somente ao atual. O virtual possui uma plena realidade enquanto virtual. Do virtual é preciso dizer exatamente o que Proust dizia dos estados de ressonância: "Reais sem serem atuais, ideais sem serem abstratos", e simbólicos sem serem fictícios. (Deleuze, 1998, p. 335). O virtual também não deve ser confundido com o possível. O possível não possui uma realidade, ele é latência antes de ser real, potência a ser real no futuro, e portanto, inexistente enquanto realidade. O virtual, ao contrário, é uma instância real, na memória, no passado, estes contraídos todos no presente do corpo que se atualiza. O corpo, como multiplicidade, sempre possuirá, portanto, virtuais e atuais reais. Este par atualvirtual também não deve ser apresentados como uma dualidade fixa. Eles se perpassam e se permeiam, coexistindo no presente. Não há objeto puramente atual. Todo atual rodeia-se de uma névoa de imagens virtuais [...] todo atual rodeia-se de círculos sempre renovados de virtualidades, cada um deles emitindo um outro, e todos rodeando e agindo sobre o atual. (Deleuze in Alliez, 1996, p.49). 
tando-a. Essa dupla seta, dupla abertura, afetar/ ser afetado, coloca o corpo-em-estado-cênico em relação com o público e com o outros atores, além de defini-lo e alimentá-lo em suas (re)recriaçóes. Vinculo diretamente o corpoem-estado-cênico a zona de turbulência justamente para sublinhar que essa zona somente poderá ser gerada a partir de um corpo-em-estado-cênico. Com isso quero dizer que, mesmo acreditando no caráter absolutamente vinculado entre teatro e jogo, não posso partir apenas e tão somente do jogo para criar um espetáculo teatral. $\mathrm{O}$ jogo somente se estabelece através do corpo-em-estado-cênico e esse deverá ser buscado e agenciado através de todo trabalho prático-técnico anterior. Talvez o difícil de entender aqui seja esse caráter paradoxal e de multiplicidade desse mesmo corpo-em-arte, pois ao mesmo tempo que é ele quem gera a zona de turbulência, de jogo, ele também deve habitalo, afetar e ser afetado pela mesma zona criada por ele.

A existência dessa zona de turbulência, zona "entre", zona que afeta e é afetada pelo ator e pelo espectador ao mesmo tempo, acaba gerando uma grande instabilidade no Estado Cênico, fazendo com que um espetáculo nunca seja exatamente igual a outro, por mais absolutamente codificado e amarrado que ele seja. Todo acontecimento teatral é completamente instável em vários níveis dentro de sua aparente estabilidade. Primeiro, uma instabilidade no nível do própria relação entre corpo-em-estadocênico e corpo cotidiano, pois já que uma ação física ou matriz nunca será repetida, mas recriada num continuum ziguezague, qualquer alteração do "estado momento" do corpo cotidiano (uma forte gripe, febre, um abalo emocional) pode, mais ou menos, afetar a recriação do corpo-em-estado-cênico. Afetando sua recriação, afetaremos a criação da própria zona de turbulência, gerando um instabilidade em segundo nível, já que o corpo-em-estado-cênico cria, gera, afeta e é afetado pela zona de turbulência. Finalmente, essa zona de turbulência, criada e dependente do corpo-em-estado-cênico já ins- tável, pois sempre subordinado a uma recriação, define-se pela própria criação de instabilidade no acontecimento teatral, criando, em si, um terceiro nível de instabilidade. Assim, em um plano espetacular, o corpo-em-estado-cênico, ao mesmo tempo gera, habita e é definido pela própria zona de turbulência e possibilita o afetar e o ser afetado pelo espaço, pelo outro ator, e pelo público que jamais é igual. A zona de turbulência é uma zona de forças em relação gerando instabilidades e estabilidades sempre em continuum. Dessa forma, o corpo cotidiano recria as matrizes que recriam o corpo-em-estado-cênico em continuum, que, por sua vez, cria, gera e habita uma zona de turbulência, local/ espaço que engloba o próprio corpo-em-estadocênico, o espaço cênico e o público e no qual todos esses elementos se afetam e são afetados. Zona de turbulência: local/espaço no qual tudo ao mesmo tempo se acumula, se conecta, se desconecta, se atualiza, se virtualiza, se diagonaliza; tudo se auto afeta e recria-se a cada momento. Multiplicidade auto gestante. O corpo-emestado-cênico passa a ser, dessa forma, um sistema que se auto-determina, auto-gere. Não são os elementos isolados, esse ou aquele, seja energia, impulsos, formalizaçōes espaço/temporais, zona de turbulência, um ou outro elemento pré-expressivos que determina o corpo-emestado-cênico. Ao mesmo tempo essa mesma definição também não pode vir de uma simples somatória de todos esses elementos. $\mathrm{Na}$ verdade, o corpo-em-estado-cênico é um fluxo em continuum dinâmico de relaçóes de todos esses elementos que se auto gerem, auto destroem, auto criam-se uns aos outros, numa relação lógica indiscernível. Maturana e Varela propuseram, no nível biológico, que um sistema vivo caracteriza-se por essa circularidade auto-produtora: um sistema que se auto-gere, auto-sustenta:

Naquele momento, também percebi que não é o fluxo de matéria ou fluxo de energia como fluxo de matéria ou energia, nem nenhum componente particular como componentes com propriedades especiais o que de fato faz 
e define o ser vivo como tal. Um ser vivo ocorre e consiste na dinâmica de realização de uma rede de transformaçōes e de produçōes moleculares, de maneira tal que todas as moléculas produzidas e transformadas no operar dessa rede fazem parte da rede [...] percebi que o ser vivo não é um conjunto de moléculas, mas uma dinâmica molecular, um processo que acontece como unidade separada $\mathrm{e}$ singular como resultado do operar e no operar. Das diferentes classes de moléculas que a compóe, em um interjogo de interaçōes e relaçōes de proximidade que o especificam como uma rede fechada de câmbios e sínteses moleculares que produzem as mesmas classes de moléculas que a constituem, configurando uma dinâmica que ao mesmo tempo especifica em cada instante seus limites e extensão. (Maturana e Varela, 2002, p. 15) ${ }^{3}$

Maturana e Varela deram o nome a esse sistema que se auto-gere em circularidade de um sistema autopoiético e definiram os seres vivos como máquinas autopoiética. Máquina aqui nāo deve ser entendida em sua relação meramente mecânica, mas como uma unidade funcional determinada pela inter-relação de seus componentes. Ou ainda como "o conjunto da inter-relação de seus componentes, independentes de cada componente" (Varela in Guatarri, 1992, p. 34). O termo autopoiese, ou sistema autopoiético, aca- bou saltando dos limites da biologia e não é raro ser usado na definição de relaçóes socais, culturais e até mesmo familiares e comunicacionais. ${ }^{4}$ Mas não quero dizer que o corpo-em-estadocênico seja uma máquina autopoiética, pois esse termo define um universo biológico de sistemas fechados em si. Coloco aqui essas questōes para dizer que o caráter de auto produção já é verificado em nível biológico molecular, como um sistema autopoiético, e mesmo para definir relaçóes de auto-produção em sistemas de ordem superior, como nas relaçóes sociais. Esse conceito não é novo. Portanto posso dizer que o corpo-em-estado-cênico pode ser considerado uma máquina estética e de jogo, que se define pela inter-relaçāo e auto-produção em continuuns dinâmicos desvanecentes de seus componentes $e$ que somente existe no momento da atuação. É nesse sentido que, tanto a apresentação de um espetáculo como a construção de um corpo-emestado-cênico é um acontecimento, uma beccei$d a d e^{5}$, que se auto cria de forma única e efêmera em instantes de continuidade, tendo, dentro de cada instante um infinito coexistente. Assim o espetáculo teatral é um grande acontecimento, uma grande hecceidade permeada por pequenos acontecimentos, pequenas hecceidades que são criaçóes e recriações numa dinâmica continua desvanescente e efêmera, seja do corpo-emestado-cênico, seja de cada espectador que participa desse mesmo acontecimento.

3 Trecho retirado do prefácio intitulado "Vinte Anos Depois" de Humberto Maturana à segunda edição da obra em questáo.

4 Exemplos gerais desse uso podem ser verificados nos próprios prefácios de Maturana e Varela na segunda ediçáa do livro "De máquinas e Seres Vivos - Autopoiese a organização do vivo", incluído críticas a uma possível desvirtuação do termo em outros planos. Um exemplo pontual pode ser encontrado em Caosmose, de Feliz Guatarri, principalmente Oralidade Maquínica e Ecologia do Virtual.

5 Hecceidades seriam, segundo Deleuze e Guatarri, acontecimentos; são o que poderíamos chamar de subjetivação de uma hora, de um dia, de uma tarde, de um beijo, de um adeus. As hecceidades são pontos de intensidade desse plano, velocidades, movimentos e repouso de moléculas e partículas, poder de afetar e ser afetado. (Deleuze e Guatarri, 1997, p. 47). É um modo intensivo de existência e náo um sujeito pessoal (Deleuze, 2000, p. 123), e é nesse sentido que esse campo de intensidades não possuí Sujeitos imutáveis, mas sim Processos de Subjetivação que são acontecimentos, hecceidades. 
Mas ao ler as linhas acima pode parecer que essa grande instabilidade proporcionada pelo corpo-em-estado-cênico como máquina estética e de jogo na auto criação da zona de turbulência e suas duplas setas de afetar e ser afetado acabe gerando espetáculos completamente abertos, sem qualquer formalização no espaço/tempo. Mas sabemos que não é isso que acontece. A não ser que ocorra algo muito fora do contexto esperado, como por exemplo, um branco no texto de um dos atores, uma falta de energia elétrica, um objeto que cai, um grande barulho externo, um telefone celular que toca, um erro de alteração de uma marcação de cena etc, os espetáculos, ao menos os do LUME, apresentam sempre a mesma construção espaço/temporal. Claro que alguns espetáculos sublinham essa construção no nível de detalhes de micro açóes dos atores que são recriadas mais ou menos sempre da mesma forma visível; outros, como os espetáculos de palhaços, possuem uma clara linha dramática e codificaçōes de estados e macro ações, apenas mais abertas à zona de turbulência, com setas mais longas de ser afetado, outros ainda misturam o comprimentos dessas setas na zona de turbulência; mas todos, sem exceção, possuem um nível organizacional extremo. Claro que a zona de turbulência e a dupla seta AFETAR-SER AFETADO no corpo-em-estado-cênico permite aos atores "improvisar" e se re-adaptarem quando alguma macro alteraçáo acontece vinda do exterior. Mas quando digo zona de turbulência e instabilidade do espetáculo, o estou dizendo muito mais dentro de uma zona intensiva, virtual, não extensa. É claro que, nas relações corporais visíveis, quase sempre o espetáculo transcorre dentro da mesma formalização espaço/temporal, dentro de uma aparente tranqüilidade, de uma constante estabilidade. Algumas exceções nesse sentido, talvez possam ser feitas aos espetáculos de palhaços. Mas nessa zona de afetação tudo ocorre de maneira instável, em constante turbulência, afetando as micro ações e micro pontuaçóes do ator e esse afetado, afeta o espectador, dentro da zona intensiva incorpórea criada pelo corpo-em-estado-cênico. Em seu estado atual, o espetáculo encontra-se em uma zona de organizaçáo, mas essa mesma zona é suportada e entrelaçada por uma outra zona virtual de completa instabilidade, de forças que se entrecruzam, de devires moleculares e imperceptíveis que o habitam. Uma zona comum de vizinhança na qual as partículas do corpo-em-estado-cênico entram em zona de vizinhança com partículas dos espectadores, criando uma zona de total turbulência que afeta a todos em micro percepçōes. O plano de organizaçāo do corpoem-estado-cênico e seu plano intensivo não são contrários, nem opostos, mas entrelaçados. Um dependo do outro, um gera o outro num sistema maquínico estético auto gestor. Uma zona de turbulência, zona de jogo jamais se sustentaria sem um plano completamente formal que apóia o plano intensivo dentro dele mesmo. Devemos lembrar o que nos diz Huizinga sobre o jogo e o homo ludens:

Reina dentro do domínio do jogo uma ordem específica e absoluta. [...] Ele cria ordem, é ordem, Introduz, na confusão da vida e na imperfeição do mundo uma perfeição temporária e limitada, exige uma ordem suprema e absoluta: a menor desobediência a esta, "estraga o jogo", privando-o de seu caráter próprio e de todo e qualquer valor. É talvez devido a essa afinidade profunda entre a ordem e o jogo, que este, como assinalamos de passagem, parece estar em tão larga medida ligado ao domínio da estética. (Huizinga, 2001, p. 13).

É nessa zona intensiva, zona de turbulência incorpórea, zona de instabilidade, creio eu, que o corpo-em-estado-cênico encontra sua força poética, estética e revolucionária. $\mathrm{Na}$ verdade, a própria atuação, em seu caráter formal, mergulha dentro dessa zona. É nessa zona incorpórea, virtual, não-presente, invisível, mas completamente real e imanente, que o corpoem-estado-cênico conecta-se com o outro ator e com o público. Enquanto ator, nessa zona, 
posso dizer que sou eu e não sou eu ao mesmo tempo: diluo-me através de todos os elementos formais, técnicos, virtuais, corpóreos e físicos em uma virtualização que me lança, junto com o espectador, em um outro tempo e um outro espaço, um espaço de possibilidades, de contato, de jogo, de Arte. Um plano de composição e consistência que se gera e se recria a todo instante através de mim, enquanto corpo-em-estado-cênico. A Zona de Turbulência é um plano de contágio, de acontecimento, de hecceidade. Não mais ator nem espectador, mas algo que se passa "entre" os dois. Um jogo real de potência de vida e criação. Assim, uma ação, um suposto "personagem", não vive em si, nem no corpo do ator, nem na imaginaçáo do espectador, mas na intersecçáo entre um corpo-em-estado-cênico e um espectador. Vibra no ponto "entre".

O corpo-em-estado-cênico, nessa zona de turbulência não é uma ação, nem um corpo, muito menos e nunca um personagem, ele é um estado "entre" todos os elementos que o compóe, "entre" o corpo cotidiano do ator e dos espectadores, um "entre" não pontualizável, não localizável, sem regras formais nem informais, apenas um "entre" de partículas em velocidades infinitas que se cruzam entrecruzam, zona de devir, de potência de contágio, de aliança. Zona total de contaminação, de peste. Sim, peste: e como Artaud sonhou, gritou e berrou com isso de uma forma completamente solitária!

Decididamente essa zona de turbulência intensiva não tem nada de transcendente no sentido de uma ascese a qualquer infinito, absoluto ou espiritual. É uma zona de potência proporcionada pela imanência atual e virtual do corpo-em-arte, e ao meu ver, isso em nada diminui seu caráter poético e estético, mas os amplia a possibilidades quase infinitas: a vida pela vida, os homens pelos homens em aliança, os corpos pelos corpos em contaminação, todos em sua simples pequenez, infinita finitude, sem qualquer além, aquém, mas com um absoluto poder de criação, de auto criação, de revolução em si. Potência, potência, potência, sempre gritou Nietzsche. Uma zona de forças em relação, poder de afetar e de ser afetado, gerando um maior poder/força de ampliação de açáo, verificando a possibilidade de linha de fuga e de reconstrução e renovação da novas possibilidades de vida. Poder usado em seu caráter de força útil, na dobra dele mesmo no corpo cotidiano e seu transbordamento no corpo-em-estado-cênico. Alegria, alegria - ecoa ao longe a voz de Spinoza. Uma zona, não de transcendência, mas sim de um campo transcendental que deriva da própria imanência do corpo, que acontece em hecceidades, e que dura apenas o instante do espetáculo e de cada ação/matriz desvanecentes.

Zona de Turbulência: uma zona que nos lança em um momento maravilhoso, de constante movimento instável, momento que todos, ator e público se diluem em um ponto "entre", virtual, não localizável, mas completamente real e a que todos chamamos simplesmente de Teatro. 


\section{Referências Bibliográficas}

ALLIEZ, É. A Assinatura do Mundo. Trad. de Maria Helena Rouanet e Bluma Villar. São Paulo, Editora 34, 1994.

Deleuze: Filosofia Virtual. Trad. de Heloisa B.S. Rocha. São Paulo. Editora 34, 1996.

DELEUZE, G. \& GUATTARI, F. O que é Filosofia. Trad. de Bento Prado Jr e Alberto Alonso Muñoz. - Rio de Janeiro, Editora 34, 2000.

. Mil Platôs: Capitalismo e Esquizofrenia. Vol. 1. Trad. de Aurélio Guerra Neto, Célia Pinto Costa - Rio de Janeiro, Editora 34, 1995.

Mil Platôs: Capitalismo e Esquizofrenia. Vol. 2. Trad. de Ana Lúcia de Oliveira e Lúcia Cláudia Leão - Rio de Janeiro, Editora 34, 1995.

. Mil Platôs: Capitalismo e Esquizofrenia. Vol. 3. Trad. de Aurélio Guerra Neto, Ana Lucia de Oliveira, Lúcia Cláudia Leão e Suely Rolnik. Rio de Janeiro, Editora 34,1996.

. Mil Platôs: Capitalismo e Esquizofrenia. Vol. 4. Trad. de Suely Rolnik. Rio de Janeiro, Editora 34,1997.

. Mil Platôs: Capitalismo e Esquizofrenia. Vol. 5. Trad. de Peter Pál Pelbart e Janice Caiafa.

Rio de Janeiro, Editora 34,1997.

. O Anti Édipo. Trad. Georges Lamaziére. Rio de Janeiro, Imago, 1976.

DELEUZE, G. \& PARNET, C. Diálogos. Trad. de Eloísa Araújo Ribeiro. São Paulo, Editora Escuta, 1998.

DELEUZE, G. Conversaçōes. Trad. de Peter Pál Pelbart. São Paulo, Editora 34, 1992.

. Espinoza e os Signos. Trad. de Abílio Ferreira. Porto, Editora Rés, s./d.

1991

A Dobra - Leibniz e o Barroco. Trad. de Luís B.L. Orlandi. Campinas, Editora Papirus,

Diferença e Repetição. Trad. de Luís B.L. Orlandi e Roberto Machado. Rio de Janeiro, Graal. 1988 (1)

. Lógica do Sentido. Trad. de Luís Roberto Salinas Fortes. São Paulo, Perspectiva. 2000.

Bergsonimo. Trad. de Luiz B. L. Orlandi. São Paulo, Editora 34, 1999.

Foucault. Trad. de Claudia SantÁnna Martins. Revisão Janine Ribeiro. São Paulo, Editora Brasiliense, 1988.

GUATTARI, F. Caosmose; um novo paradigma estético. Trad. de Ana Lúcia de Oliveira e Lúcia Cláudia Leão. São Paulo, Editora 34, 1992.

HUIZINGA, J. Homo ludens: o jogo como elemento da cultura. Trad. de João Paulo Monteiro. São Paulo, Perspectiva, s./d.

MATURANA, H. R. e VARELA, F. G. De Máquinas e Seres Vivos. Sao Paulo, ArtMed, 2002. 